\title{
Poly(acrylic acid-co-methyl methacrylate)/metronidazole systems: synthesis and complexation*
}

\author{
Katarzyna Bialik-Wąs ${ }^{\bowtie}$ and Krzysztof Pielichowski \\ Department of Chemistry and Technology of Polymers, Cracow University of Technology, Kraków, Poland
}

\begin{abstract}
We report on preparation of poly(acrylic acid-co-methyl methacrylate) (PAM) micro- and nanoparticles and, in the subsequent stage, complexation reaction with the active substance - metronidazole (MET). The drug release behavior of MET - loaded PAM micro- and nanoparticles was evaluated in water and phosphate buffered saline (PBS, $0.9 \% \mathrm{NaCl}$ ) at $37^{\circ} \mathrm{C}$. It has been found that introduction of MET into PAM micro- and nanoparticles enabled gradual and controlled release of the active substance. Structural analysis using FT-IR (ATR) and ${ }^{1} \mathrm{H}$ NMR, as well as surface morphology assessment by SEM, were performed.
\end{abstract}

Key words: metronidazole, poly(AA-co-MMA), drug delivery systems

Received: 22 October, 2013; revised: 05 December, 2013; accepted: 05 December, 2013; available on-line: 29 December, 2013

\section{INTRODUCTION}

Nowadays, medicine and pharmacy require improved drug delivery systems targeting only on the areas covered by the diseases. These conditions can meet the micro- and nanoparticles based on polymers, $\mathrm{pH}$-sensitive hydrogels, biopolymer-based microgels/nanogels (biomicrogels/bionanogels) (Agnihotri et al., 2004; Bajpai et al., 2008; Liu et al., 2008). The controlled drug delivery systems are truly important in treatment of human diseases due to their therapeutic advantages in improving bioavailability and minimizing systemic side effects. The ideal controlled release system is intended to provide constant level of active substance in plasma (Nafea et al., 2011). In recent years, increased interest around combination of natural polymers such as polysaccharides, proteins with synthetic for the preparation of drug delivery systems, is observed. According to literature, numerous systems based on chitosan, gelatin or starch with poly(N-vinyl pyrrolidone) (PVP), poly(methyl methacrylate) (PMMA), poly(2-hydroxyethyl methacrylate) (PHEMA) or polycarboxylate have been designed (Dudhania \& Kosarajua, 2010; Eftaiha et al., 2010; Nafea et al., 2011). They are used as thermoand $\mathrm{pH}$-sensitive vesicles, polymeric micelles and micro- and nanospheres (Robinson \& Peppas 2002; Felber et al., 2012; Nguyen et al., 2011; Dong et al., 2011). Among different active substances metronidazole 2-(5-nitro-2-methylimidazol-1-yl)-ethanol (MET) - is a well-known antimicrobial agent commonly used in clinical medicine for $>45$ years. Mainly it is used to treat parasitic infections including Giardia infections of the small intestine, amebic liver abscess, amebic dysentery (infection of the colon causing bloody diarrhea), bacterial vaginosis and trichomonas vaginal infections.
Metronidazole is often used in the production of ointments, which are applied in the treatment of chronic wounds, mainly bedsores (Lofmark et al., 2010; Herculano et al., 2011).

Hence, in this work we focused on preparation of biologically-stable poly(acrylic acid-co-methyl methacrylate) micro- and nanoparticles and their complexation with MET. The synthesis of poly(acrylic acid-co-methyl methacrylate) micro- and nanoparticles is carried out in an aqueous medium, allowing to eliminate any toxic and harmful solvent.

\section{MATERIALS AND METHODS}

Acrylic acid (AA, monomer) and ammonium persulfate (APS, initiator) were purchased from POCh Gliwice, Poland, poly(ethylene glycol) diacrylate (PEGDA $\mathrm{Mn}=575$, crosslinker) and methyl methacrylate (MMA, monomer) were acquired from Sigma Aldrich, metronidazole was obtained from Pharma-Cosmetic, Poland.

Preparation. In this study, PAM particles with feed molar ratios AA:MMA $=7: 3$ and total monomer concentration $0.3 \mathrm{mM}$ were used for metronidazole loading (3\% relative to the total monomer content). Acrylic acid and MMA were polymerized using $100 \mathrm{mg}$ of APS as initiator and $100 \mu \mathrm{l}$ of PEGDA (Mn = 575) as crosslinking agent in $200 \mathrm{ml}$ of distilled water as solvent. The reaction was carried out at $80^{\circ} \mathrm{C}$ under nitrogen for $8 \mathrm{~h}$ by using mixing speed 1000 r.p.m., whereas MET was dispersed in distilled water and mixed with micro- and nanoparticles as an aqueous suspensions. The complexation was conducted for $24 \mathrm{~h}$ at room temperature (Yan \& Gemeinhart, 2005; Vijay et al., 2010; Bialik-Wąs et al., 2013).

Copolymer characterization. Fourier transform infrared (FT-IR) attenuated total reflectance (ATR) spectroscopy. FT-IR (ATR) spectra were recorded using Spectrum 65 (Perkin Elmer) spectrometer. All spectra (32 scans at $4.0 \mathrm{~cm}^{-1}$ resolution) were recorded at $25^{\circ} \mathrm{C}$. The obtained PAM and MET-loaded PAM systems spectra were in the $4000-600 \mathrm{~cm}^{-1}$ range.

${ }^{1} \mathrm{H}$ nuclear magnetic resonance ( ${ }^{1} \mathrm{H}$ NMR). The chemical structure of PAM and MET-loaded PAM compositions were characterized with

e-mail: kbialikwas@chemia.pk.edu.pl

*Presented at the 5th Central European Congress of Life Sciences "EUROBIOTECH 2013", Kraków, Poland.

"Abbreviations: AA, acrylic acid; APS, ammonium persulfate; ATR, Attenuated total reflectance; FT-IR, Fourier transform infrared; MET, 2-(5-nitro-2-methylimidazol-1-yl)-ethanol; MMA, methyl methacrylate; PHEMA, poly(2-hydroxyethyl methacrylate); PEGDA, poly(ethylene glycol) diacrylate; PMMA, poly(methyl methacrylate); PVP, poly(N-vinyl pyrrolidone) 


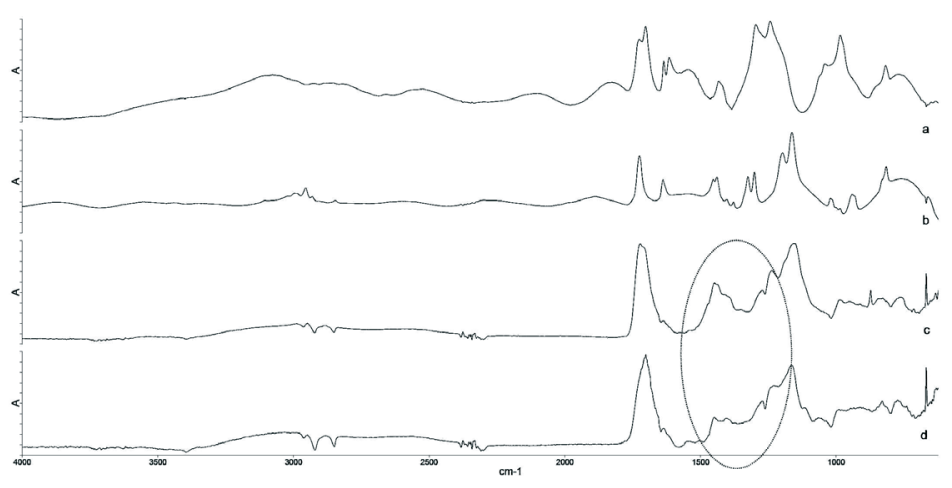

Figure 1. FT-IR spectra of:

(a) AA; (b) MMA; (c) PAM micro- and nanoparticles and (d) MET-loaded PAM systems.

${ }^{1} \mathrm{H}$ NMR (Bruker NMR Spectrometer, working at 500.13 $\mathrm{MHz}$ ). The samples were dissolved in deuterated DMSO and $\mathrm{CDCl}_{3}(1: 1)$.

Scanning electron microscopy (SEM). The surface morphology and shape of obtained PAM particles and MET-loaded PAM systems were observed using a scanning electron microscopy (JEOL JSM-6010LA).

Studies of drug release. The release profiles of metronidazole from PAM micro- and nanoparticles in water $(\mathrm{pH}=7)$, phosphate-buffered saline (PBS, $\mathrm{pH}$ $=7.4)$ ) and sodium chloride $(\mathrm{pH}=6.4)$ at $37^{\circ} \mathrm{C}$, were constructed. MET-loaded PAM, $0.0006 \mathrm{~g}$, was placed in $30 \mathrm{ml}$ of the release medium. The release experiment was conducted by $96 \mathrm{~h}$. The drug presence was confirmed by measuring absorbance at $320 \mathrm{~nm}$ by $\mathrm{UV} / \mathrm{Vis}$ absorption (Evolution 220, ThermoScientific).
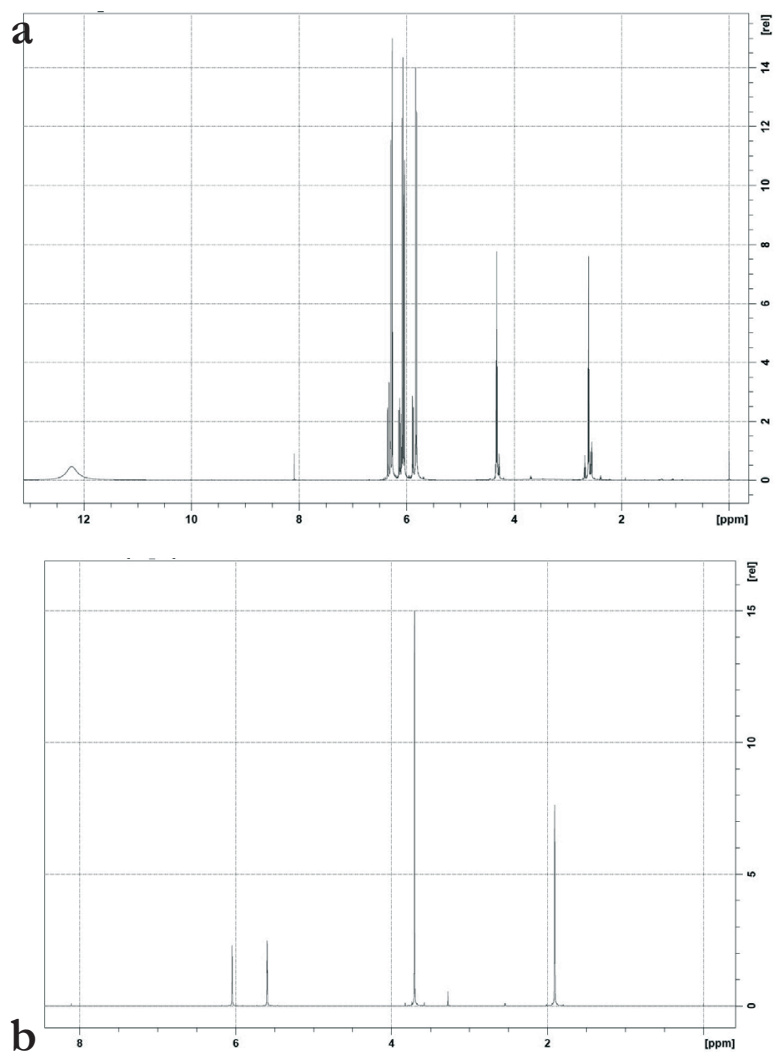

\section{DISCUSSION}

\section{FT-IR (ATR) analysis}

The obtained FT-IR spectrum confirmed that the copolymerization reaction of acrylic acid and methyl methacrylate took place (Fig. 1).

It can be observed a broad band in the $3700-2600 \mathrm{~cm}^{-1}$ range, which is characteristic for hydroxyl groups, $\mathrm{C}=\mathrm{O}$ stretching of ester group at $1713 \mathrm{~cm}^{-1}$ and symmetric carboxylate anion stretching at 1388 $\mathrm{cm}^{-1}$. In the spectra of the used monomers: AA and MMA, there are clear peaks at $1640 \mathrm{~cm}^{-1}$, which derive from the vinyl bond $\mathrm{C}=\mathrm{C}$. In the case of PAM microand nanoparticles and MET-loaded PAM there are very weak peaks around 1640 $\mathrm{cm}^{-1}$, which may orginate from monomer residues. For MET-loaded PAM, OH stretching $\left(3219 \mathrm{~cm}^{-1}\right), \mathrm{NO}_{2}$ vibrations, N-O stretching $\left(1535 \mathrm{~cm}^{-1}\right), \mathrm{C}-\mathrm{OH}, \mathrm{C}-\mathrm{O}$ stretching $\left(1074 \mathrm{~cm}^{-1}\right)$, and $\mathrm{C}-\mathrm{NO}_{2}$ stretching $\left(870 \mathrm{~cm}^{-1}\right)$ have been detected. It can be seen the $\mathrm{O}-\mathrm{H}$ stretching vibrations at $2887 \mathrm{~cm}^{-1}$ and aromatic $\mathrm{C}-\mathrm{H}$ stretching at $2951 \mathrm{~cm}^{-1}$, as well as deformation vibrations of strong intensities at 1431, $1269 \mathrm{~cm}^{-1}$ (Yan \& Gemeinhart, 2005; Silverstein et al., 2005; Vijay et al., 2010; Ramukutty \& Ramachandran, 2012).

\section{'H NMR analysis}

The obtained ${ }^{1} \mathrm{H}$ NMR spectra (Fig. 2) show that the copolymerization reaction of acrylic acid and methyl
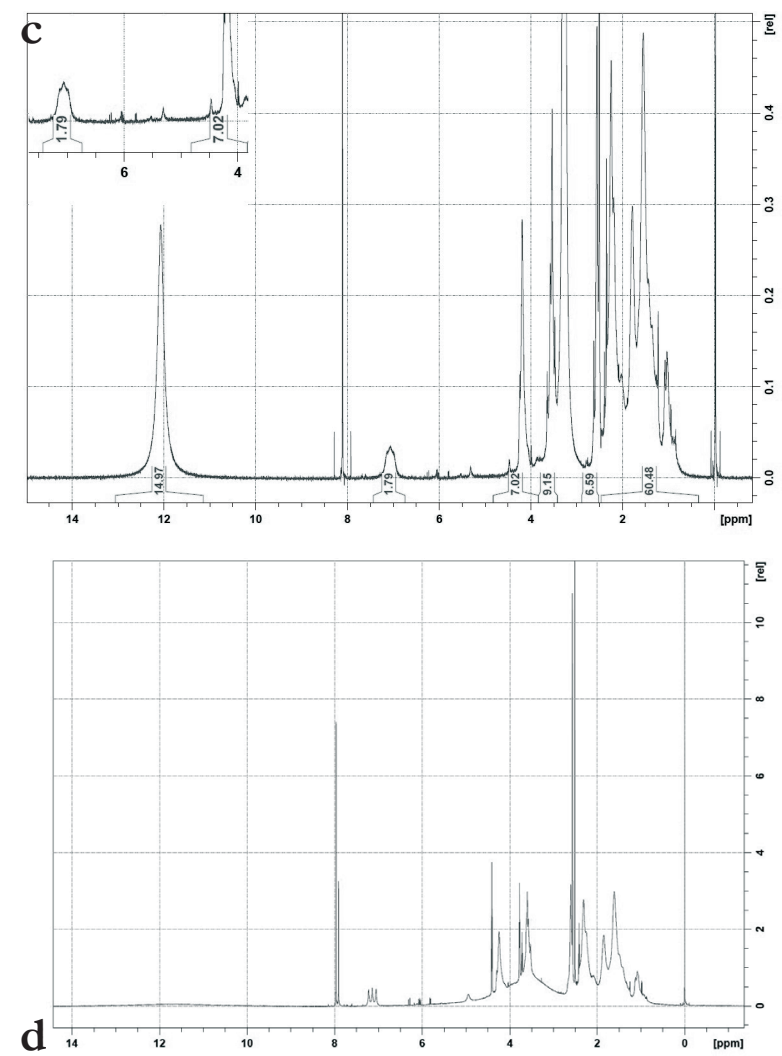

Figure $2^{1} \mathrm{H}$ NMR spectra of:

(a) AA; (b) MMA; (c) PAM micro- and nanoparticles and (d) MET-loaded PAM systems. 


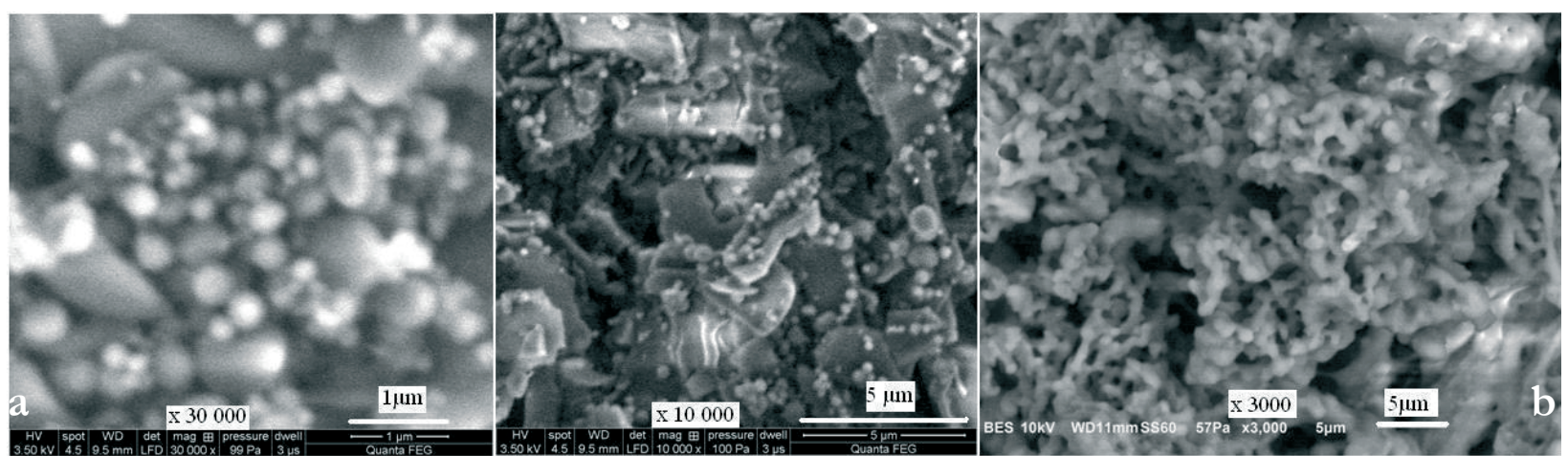

Figure 3 SEM microphotographs of:

(a) PAM micro- and nanoparticles and (b) MET-loaded PAM systems.

methacrylate occurred. In the case of spectra of monomers vinyl protons at 5.9, 6.1 and $6.5 \mathrm{ppm}$ in acrylic acid and at 5.5 and 6.1 in methyl methacrylate can be seen. These signals practically disappeared in the spectrum of PAM micro- and nanoparticles, as well as in MET-loaded PAM.

\section{SEM analysis}

On the basis of SEM microphotographs it can be concluded that a mixture of micro- and nanoparticles was obtained. The PAM micro- and nanoparticles are characterized mostly by a spherical shape.

\section{The release profiles of metronidazole from PAM micro- and nanoparticles}

The release profiles of MET from PAM micro- and nanoparticles in water $(\mathrm{pH}=7)$, phosphate-buffered saline (PBS, $\mathrm{pH}=7.4$ ) and sodium chloride $(\mathrm{pH}=6.4)$ at $37^{\circ} \mathrm{C}$ are presented in Fig. 4. The literature review show that PAM micro- and nanoparticles could be used as an enteric coating material for prolonged drug release (Yan \& Gemeinhart, 2005; Vijay et al., 2010). The release rate of active substance depends not only on $\mathrm{pH}$ of the dissolution medium, but also on chemical structure of carrier, drug-matrix interactions and physical factors such as diffusion or swelling viscosity. On the beginning, a marked jump in the amount of MET in the solution is visible. Maximum concentration of released MET is about $40 \%$ at $\mathrm{pH}$ $=7.4$ and it is slightly lower at $\mathrm{pH}=6.4$ and 7 . After 24 hours MET is still released and its concentration remains at similar level for the next hours of measurements.

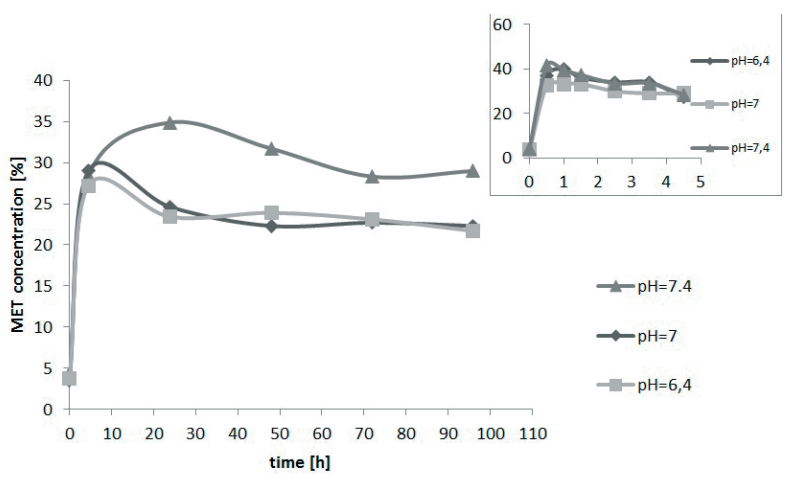

Figure. 4. The release profiles of MET from PAM micro- and nanoparticles in different medium.
In case of a higher $\mathrm{pH}$ environment, it was observed that the amount of released MET is slightly higher and concentration is approximately $28 \%$. When using $\mathrm{pH}$ $=6.4$ and 7, MET concentration is very similar and is equals to about $24 \%$. After $96 \mathrm{~h}$ concentration of released MET remains constant and does not change. MET released better in an alkaline medium, and similar results were reported in the literature (Sadeghi \& Yarahmadi, 2011, Ma et al., 2012). This effect is probably due to the presence of $\mathrm{OH}^{-}$groups that increases the electrostatic repulsions, causing thus the larger release of MET. Furthermore, the intensity of electrostatic interactions between MET and PAM systems decreased at $\mathrm{pH}$ $=7.4$, slowering the release of MET. In an neutral and slightly acidic environment, MET is more strongly associated with PAM systems, and therefore it releases with more difficulty. Based on these results it can be seen that the PAM micro- and nanoparticles allow a slow and controlled release of the active substance metronidazole.

\section{CONCLUSIONS}

The copolymerization reaction of $\mathrm{AA}$ and MMA yielded spherical shape micro- and nanoparticles of PAM, which could be applied as carriers for metronidazole (MET). The obtained FT-IR and ${ }^{1} \mathrm{H}$ NMR spectra indicate a successful copolymerization and complexation reaction with the active substance (MET). It is worth noting that the synthesis was conducted in water as a medium, without use of any harmful solvents. The release profiles show that PAM particles ensure a controlled concentration of MET over a prolonged time. On the basis of obtained results it can be concluded that poly(AA-co-MMA)-MET systems, synthesized in solventfree environment, show beneficial drug delivery profiles. However, further research on prolonged stability are necessary — such studies are in progress.

\section{Acknowledgements}

This research was supported by Polish Ministry Ministry of Science and Higher Education - project C-4/257/2013/DS-M.

\section{REFERENCES}

Agnihotri SA, Mallikarjuna NN, Aminabhavi TM (2004) Recent advances on chitosan-based micro- and nanoparticles in drug delivery. J Control Release 100: 5-28. 
Bajpai AK, Shukla SK, Bhanu S, Kankane S (2008) Responsive polymers in controlled drug delivery. Prog Polym Sci 33: 1088-1118.

Bialik-Wąs K, Tyliszczak B, Pielichowski K (2013) Synthesis and structure of poly(AA-co-MMA) micro- and nanoparticles containing metronidazole, 4th Workshop Green Chemistry and Nanotechnologies in Polymer Chemistry, 4-6.09.2013, Pisa, Italy.

Dong Y, Mu B, Liu P, (2011) Temperature-responsive ioniccrosslinked polymeric nanocapsules via self-templating approach. Colloid Surface B 84: 267-271.

Dudhania AR, Kosarajua SL (2010) Bioadhesive chitos an nanoparticles: preparation and characterization. Carbohydr Polym 81: 243-251.

Eftaiha AF, Qinna N, Rashid IS, Al Remawi MM, Al Shami MR, Arafat TA, Badwan AA (2010) Bioadhesive controlled metronidazole release matrix based on chitosan and xanthan gum. Mar Drugs 8: 1716-1730.

Felber AE, Dufresne MH, Leroux J-C (2012) pH-sensitive vesicles, polymeric micelles and nanospheres prepared with polycarboxylates. Adv Drug Deliver Rev 64: 979-992.

Herculano RD, Alencar de Queiroz AA, Kinoshita A, Oliveira ON, Graeff CFO (2011) On the release of metronidazole from natural rubber latex membranes. Mat Sci Eng C 31: 272-275.

Liu Z, Jiao Y, Wang Y, Zhou C, Zhang Z (2008) Polysaccharidesbased nanoparticles as drug delivery systems. Adv Drug Deliv Rev 60: 1650-1662.

Lofmark S, Edlund Ch, Nord CE (2010) Metronidazole is still the drug of choice for treatment of anaerobic infections. Clin Infect Dis 50: 16-23.
Ma Y, Gao H, Gu W, Yang Y-W, Wang Y, Fan Y, Wu G, Ma J (2012) Carboxylated poly(glycerol methacrylate)s for doxorubicin delivery. Eur J Pharm Sci 45: 65-72.

Nafea EH, Marson A, Poole-Warren LA, Martens PJ (2011) Immunoisolating semi-permeable membranes for cell encapsulation: Focus on hydrogels. J Control Release 154: 110-122.

Nguyen H-N, Wey S-P, Juang J-H, Sonaje K, Ho Y-C, Chuang E-Y, Hsu C-W, Yen T-C, Lin K-J, Sung H-W (2011) The glucose-lowering potentialof exendin-4 orally delivered via a $\mathrm{pH}$-sensitive nanoparticle vehicle and effects on subsequent insulin secretion in vivo. Biomaterials 32: 2673-2682.

Ramukutty S, Ramachandran E (2012) Crystal growth by solvent evaporation and characterization of metronidazole. J Cryst Growth 351: $47-50$.

Robinson DN, Peppas NA (2002) Preparation and characterization of $\mathrm{pH}-$ responsive poly(methacrylic acid-g-poly(ethylene glycol) nanospheres. Macromolecules 35: 3668-3674.

Sadeghi M, Yarahmadi M (2011) Synthesis and properties of carboxymethylcellulose (CMC) graft copolymer with on-off switching properties for controlled release of drug. Afr J Biotechnol 10: 12085-12093.

Silverstein RM, Webster FX, Kiemle DJ (2005) Spectrometric Identification of Organic Compounds, John Willey \& Sons, Inc.

Vijay S, Sati OP, Majumdar DK (2010) Acrylic acid-methyl methacrylate copolymer for oral prolonged drug release. J Mater Sci:P Mater Med 21: 2583-2592.

Yan X, Gemeinhart RA (2005) Cisplatin delivery from poly(acrylic acid-co-methyl methacrylate) microparticles. I Control Release 106: 198-208. 